\title{
THE DISTRIBUTION OF THE PERMANENT PARALYSIS IN THE LOWER LIMB IN POLIOMYELITIS
}

\author{
A Clinical and Pathological Study \\ W. J. W. Sharrard, London, England \\ From the Institute of Orthopaedics and the Royal National Orthopaedic Hospital \\ under a grant from the Medical Research Council
}

Though a striking feature of the paralysis that may result from an attack of poliomyelitis is its diversity, the belief that some order exists in the apparently irregular distribution of the permanent paralysis has been expressed by several authors. Wickman (1913) stated that " although a great variety of combinations of paralyses are found, certain types appear more often than others; in the leg the peroneal group and certain muscles of the thigh - in my experience the quadriceps femoris especially - tend to be implicated." Lovett and Lucas (1908), Lovett (1915, 1917), Jahss (1917), Mitchell (1925) and Legg (1929, 1937) showed tables indicating the relative frequency of paralysis and paresis in the muscles of the lower limb. All show a high incidence of paralysis in tibialis anterior, tibialis posterior, the long extensors of the toes and the peronei. A lower incidence of paralysis but a greater combined total of paralyses and pareses is shown in the quadriceps and in the gluteal muscles. No satisfactory explanation has yet been offered to account for these findings.

It is the object of this paper to review the distribution of paresis and paralysis in the muscles of the lower limb, to account for its disposition in terms of the destruction of motor nerve cells in the lumbo-sacral spinal cord, and to indicate the practical application of the findings in the management of poliomyelitis.

\section{THE DISTRIBUTION OF PARESIS AND PARALYSIS IN THE MUSCLES OF THE LOWER LIMB}

MATERIAL

The cases analysed in this paper were those in which a study of muscle recovery was previously reported in this Journal (Sharrard 1955). In 142 patients there were 203 lower limbs in which, three years after the onset of poliomyelitis, residual paresis or paralysis could be detected in one or more muscles by clinical examination. The seventeen muscles or muscle groups that are analysed here are the same as those described in the previous study of muscle recovery.

\section{AFFECTION OF INDIVIDUAL MUSCLES}

Of 2,464 affected muscles, 1,502 were paretic and 962 paralysed; the ratio of paresis to paralysis was $1 \cdot 56$ to $1 \cdot 0$.

The numbers of pareses and paralyses of individual muscles, and the proportions of paresis to paralysis in them, varied (Tables I and II). The main facts are that the quadriceps and the hip abductors (gluteus medius and minimus) lead in frequency of affection and in numbers of pareses, but the muscles of the leg are those most frequently paralysed. Tibialis anterior, tibialis posterior and the long flexors and extensors of the toes show low proportions of paresis to paralysis, while the hip flexors and hip adductors show a high proportion. 
The order of the muscles shown in Table I confirms Lovett's (1915) finding that the muscles nearest the trunk are more frequently affected than the distal ones. He observes that " the demands on the hip and shoulder muscles are simple and less continuous than on the muscles of the lower leg and forearm or of the hand and foot. The latter are continuously

TABLE I

The Frequency of Affection of 2,464 Muscles in the Lower Limb

\begin{tabular}{|c|c|c|c|c|c|c|}
\hline \multicolumn{5}{|c|}{ Muscle } & & \multirow{2}{*}{$\begin{array}{c}\begin{array}{c}\text { Number } \\
\text { affected }\end{array} \\
184\end{array}$} \\
\hline Quadriceps & . & . & $\theta^{\prime}$ & . & . & \\
\hline Hip abductors (gluteus m & edius & and $\mathrm{r}$ & ninim & us) & . & 178 \\
\hline Inner hamstring muscles & . & . & . & . & . & 168 \\
\hline Biceps femoris. & . & . & . & . & . & 164 \\
\hline Hip adductors . & . & . & . & . & . & 162 \\
\hline Hip flexors & . & . & . & . & . & 159 \\
\hline Tibialis anterior & . & . & . & . & . & 152 \\
\hline Tensor fasciae latae & . & . & . & . & . & 149 \\
\hline Gluteus maximus & . & . & . & . & . & 142 \\
\hline Tibialis posterior & . & . & . & . & . & 140 \\
\hline Flexor hallucis longus & . & . & . & . & . & 133 \\
\hline Flexor digitorum longus & . & . & . & . & . & 130 \\
\hline Extensor digitorum longu & & . & . & . & . & 130 \\
\hline Calf muscles (triceps sura & & . & . & . & . & 129 \\
\hline P'eronei . & . & . & . & . & . & 126 \\
\hline Extensor hallucis longus & . & . & . & . & . & 125 \\
\hline Intrinsic foot muscles & . & . & . & . & . & 93 \\
\hline Total & . & . & $\cdot$ & . & . & 2,464 \\
\hline
\end{tabular}

active in small fine complicated movements, whereas the large muscles nearest the trunk deal with coarser and less frequent movements." It is tempting, on this basis, to assume that a causal relationship exists between differences in the size and function of individual muscles and their frequency of affection by poliomyelitis.

When, however, the same muscles are arranged in order of frequency of paralysis (Table II) the picture is completely different. The largest number of paralyses are found in the distal muscles, which also agrees with Lovett's findings. To explain them he states that " the severity of the paralysis is proportionate to the weight to be met by the muscles at different levels, not because this factor influences in any way the original affection of the (nerve) cells but because it may retard the recovery of those muscles working against the greatest weight." Although this hypothesis may be attractive, it fails to explain several important discrepancies. There is a very low incidence of paralysis in the intrinsic foot muscles which, by Lovett's reasoning, should be the most frequently paralysed of all muscles in the lower limb. The number of paralysed inner hamstring muscles differs from the number

vol. $37 \mathrm{~B}$, No. 4, NOVEMBER 1955 
of paralysed biceps femoris muscles, though it should be about the same. Further, the rate of recovery in proximal and distal muscles, instead of showing the considerable differences needed to account for the complete dissimilarity between the order of the muscles in Tables I and II has been shown to be the same for all muscles in the lower limb (Sharrard 1955).

TABLE II

The Incidence of Paralysis and Paresis-in the Muscles of the Lower Limb. The Muscles are Shown in Order of Frequency of Paralysis.

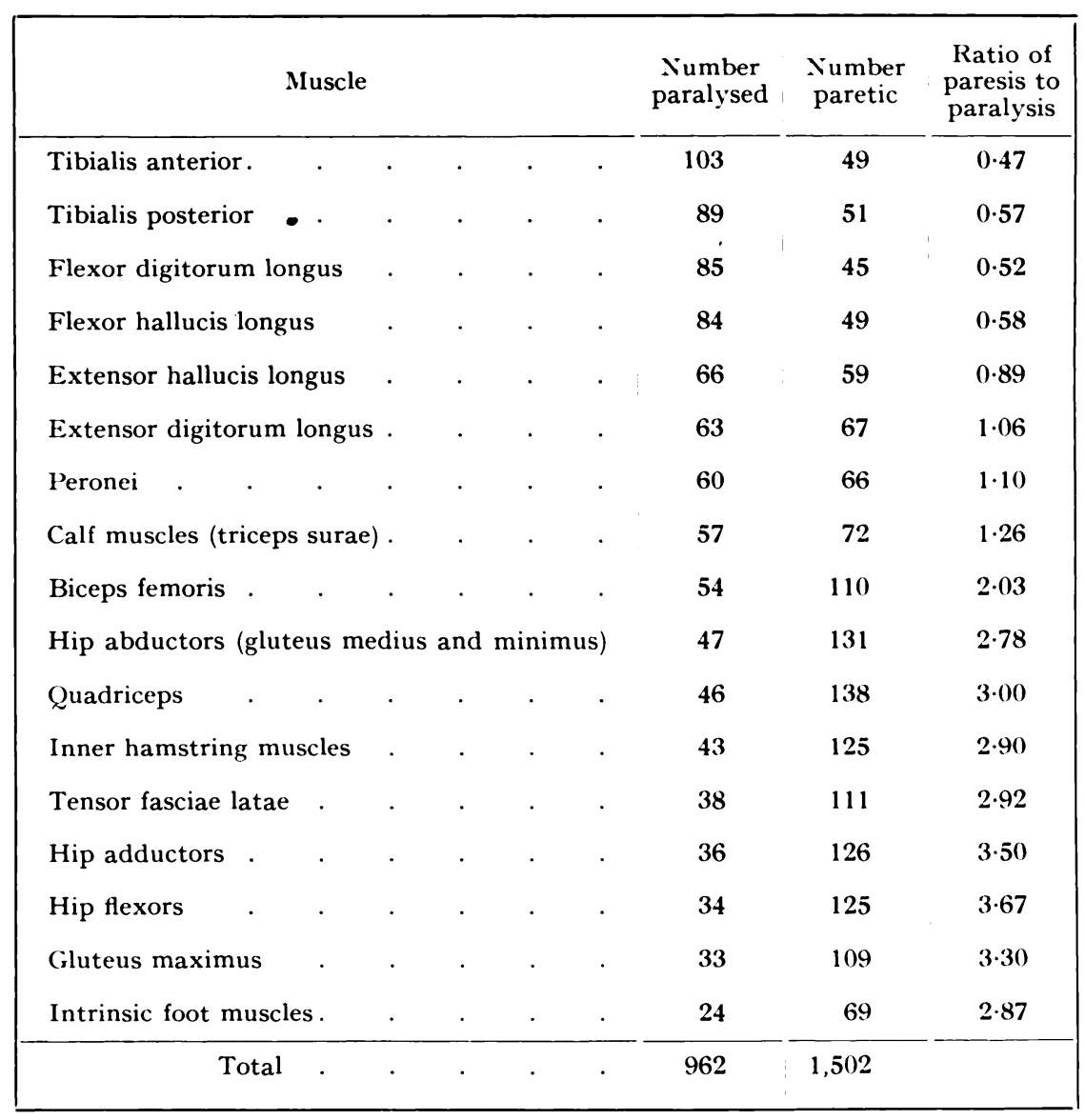

As Skinhøj (1949) observed in a similar study, there is no quality of the muscle such as size, function, position in the limb or phylogenetic development that can satisfactorily explain the frequent affection of some muscles and the high proportion of paralysis in others.

\section{ASSOCIATED PARALYSES}

That certain muscles appear to be paralysed or weakened together has been noted by several authors (Courtney 1896, Wickman 1913, Lovett 1915); their observations were, unfortunately, incomplete and relied on clinical impressions rather than on numerical analyses.

The muscle charts of the 203 lower limbs in this series were reviewed to find out whether those impressions were correct, and to reveal associations of paralysis that might otherwise be overlooked. Coincident sparing or absence of paralysis in muscles, which is equally important and likely to escape clinical observation, was also noted. Each muscle or muscle 
group was paired in turn with every other muscle. The number of times that both were paralysed in the same limb, that both were not paralysed, or that one was paralysed and the other not, was noted. The number of times that coincidence or contrariety of paralysis could occur purely by chance was also calculated. Differences between the expected and the observed findings were worked out and submitted to statistical analysis.

The assessment of statistical significance by the $x^{2}$ test gave a strongly positive result for all muscle pairs, the association factor for the most strongly associated pairs being more than two hundred times the minimum figure for statistical significance. A muscle pair was considered to be very strongly associated if the association factor was more than one hundred and fifty times the minimum.

T.IBLE III

Associated Paralyses in the Lower limb

Muscles in heavy type are very strongly associated; those in normal type are strongly associated

\begin{tabular}{|c|c|c|c|c|c|c|}
\hline \multicolumn{6}{|c|}{ Muscle } & \multirow{2}{*}{$\begin{array}{l}\text { Associated muscles } \\
\text { lductors }\end{array}$} \\
\hline Hip tlexors (psoas) & & . & . & . & . & \\
\hline Adductors & . & . & · & . & . & Quadriceps, inner hamstring muscles, hip flexors \\
\hline Quadriceps . & . & . & . & . & . & Hip flexors, adductors, inner hamstring muscles \\
\hline \multicolumn{3}{|c|}{ Inner hamstring muscles. } & . & . & . & Adductors, quadriceps, hip abductors \\
\hline \multicolumn{6}{|c|}{ Hipabductors (gluteus mediusand minimus) } & Gluteus maximus, biceps femoris, tensor fasciae latae \\
\hline Tensor fasciae lata & & . & . & . & . & Hip abductors, gluteus maximus \\
\hline Giluteus maximu; & . & . & . & . & . & Hip abductors, biceps femoris, tensor fasciae latae \\
\hline Biceps femoris & . & . & . & . & . & (iluteus maximus, hip abductors, calf muscles \\
\hline Calf muscles (trice & ps sur & & . & . & . & Biceps femoris, flexor digitorum longus \\
\hline Flexor hallucis lon & gus & . & . & . & . & Flexor digitorum longus, extensor hallucis longus \\
\hline Flexor digitorum 1 & longus & . & . & . & . & Flexor hallucis longus, extensor hallucis longus \\
\hline Extensor hallucis & Iongus & . & . & . & . & $\begin{array}{l}\text { Extensor digitorum longus, peronei, flexor hallucis } \\
\text { longus }\end{array}$ \\
\hline Extensor digitoru & $n$ long & & . & . & 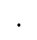 & Extensor hallucis longus, peronei \\
\hline J'eronei. & . & . & . & . & . & Extensor digitorum longus, extensor hallucis longus \\
\hline Tibialis anterior & . & . & . & . & . & Tibialis posterior \\
\hline Tibialis posterior & . & . & . & . & . & Tibialis anterior, extensor hallucis longus \\
\hline Intrinsic foot must & cles & . & . & . & $\cdot$ & Calf muscles, peronei \\
\hline
\end{tabular}

The results are given in Table III. Some associated paralyses-for instance between the long toe extensors and the peronei or between the hip abductors (gluteus medius and minimus) and the gluteus maximus-might be explained by the closely allied functions of the muscles, as had been suggested by Lovett (1915). Other associations, such as those between the calf muscles (triceps surae) and the biceps femoris (first described by Bennett in 1952) or between the quadriceps, the hip adductors and the hip flexors cannot be accounted for so easily.

The absence of a strong association between the inner hamstring muscles and the biceps femoris or between the long toe flexors and the intrinsic foot muscles provides further evidence against the theory that associated function leads to associated paralysis of muscles.

Vol. 37 B, No. 4, NOVEMBER 1955

$\mathrm{B}_{1+1}$ 
SEGMENTAL INNERVATION IN RELATION TO AFFECTION OR PARALYSIS OF MUSCLES

If the paralysis in a muscle is not related to any feature of the muscle itself, there remains the possibility that it may be related to its innervation, or, more precisely, to the site and extent of changes in the motor cells of the anterior horn of the spinal cord.

Evidence of such a relationship is given by an enquiry into the segmental incidence of muscle affection. For each spinal segment, the total number of affected muscles that receive

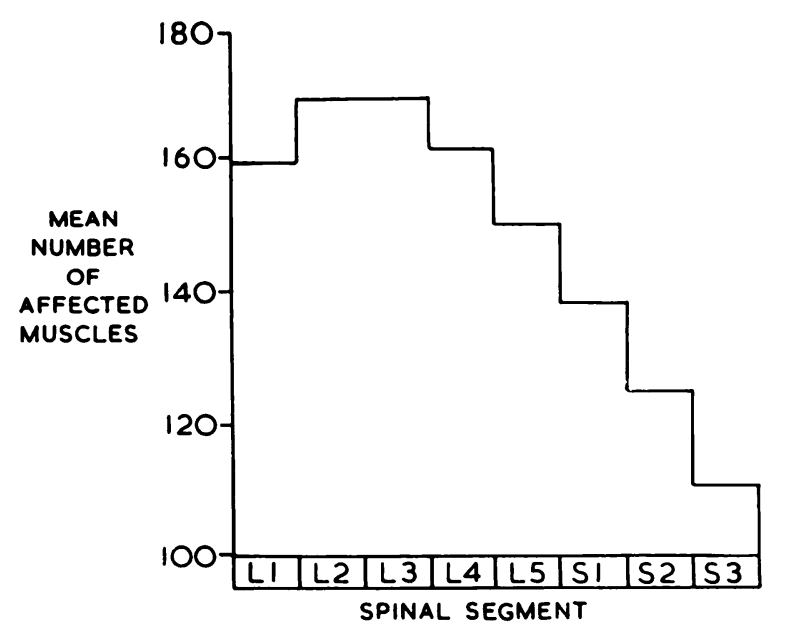

FIG. 1

The segmental incidence of affection of muscles in the lower limb.

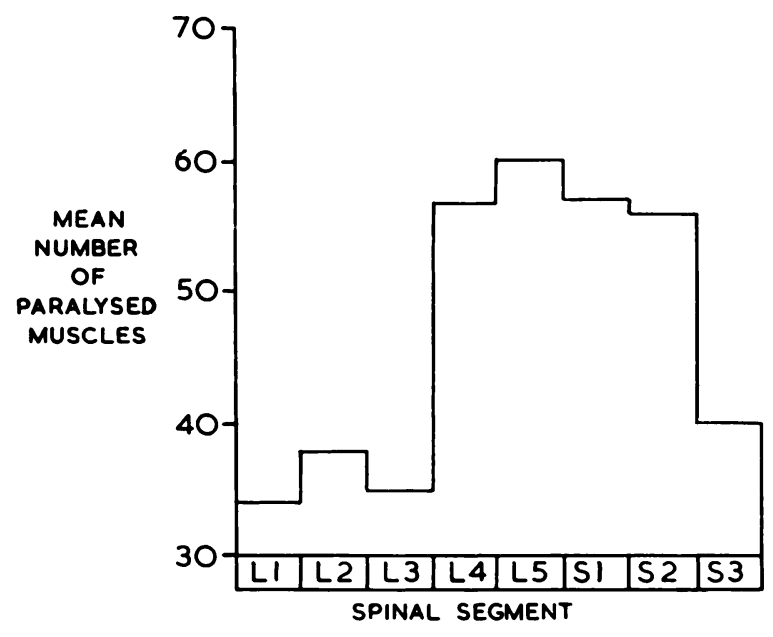

FIG. 2

The segmental incidence of paralysis of muscles in the lower limb.

a supply from the segment were noted; thus, in the third lumbar segment, the muscles were the hip flexors (159), the hip adductors (162) and quadriceps (184). The mean-in this segment 168-was calculated and used to plot a curve (Fig. 1), which thus represents the segmental incidence of muscle affection. The highest incidence is found in the second and third lumbar segments; below this level, there is a uniform decrease in the numbers of affected muscles that successive spinal segments supply.

The segmental incidence of paralysis (Fig. 2), derived in the same way from the data in Table II, is altogether different. It is included for comparison with an almost identical curve 
obtained in the same way by Seddon et al. (1945) in an analysis of a large number of cases of poliomyelitis in the Malta epidemic of 1942-43. A high incidence is found in all spinal segments between the fourth lumbar and the second sacral segments; the curve, unlike that in Figure 1, is irregular and does not indicate that there is any direct relationship between segmental innervation and frequency of paralysis.

Attempts by earlier authors (Lovett 1915, Skinhøj 1949) to explain similar findings in terms of spinal cord lesions were hampered by the paucity of information concerning the localisation of function in the motor cells in man and by the incomplete accounts of the sites of destruction of these cells in poliomyelitis.

Five years ago a study of normal and poliomyelitic spinal cords was begun; the results, a summary of which will be given here, account for all the clinical phenomena of muscle affect, paralysis and association of paralysis described above.

\section{THE SPINAL CORD IN THE NORMAL AND IN POLIOMYELITIS}

\section{METHOD OF STUDY}

The principles underlying the study of the spinal cord in poliomyelitis are simple. Spinal cords were obtained from seven patients who had died at intervals varying between three months and eight years after the onset of the disease. The level of paralysis in the muscles of their lower limbs had been estimated by clinical examination and, whenever possible, confirmed at autopsy. The position and number of residual motor nerve cells in the lumbosacral spinal cord was determined and compared with the corresponding cells in the normal.

\section{THE MOTOR GELL COLUMNS OF THE LUMBO-SACRAL SPINAL CORD}

In practice, the analysis of spinal cords proved to be a formidable task. Previous descriptions of the topography of the motor nerve cells in the anterior horn of the grey matter proved, with few exceptions (van Gehuchten and de Neeff 1900, Bruce 1901, Romanes 1941, Elliott 1942), to be quite inadequate and a separate study of three normal spinal cords had to be made.

A method of reconstruction, by projection microscopy, of the nerve cell content of the lumbo-sacral spinal cord was devised (Sharrard 1953); serial sections were cut from the upper end of the twelfth thoracic spinal segment to the filum terminale, stained with eosin-azure, and the position, size and number of nerve cells in each successive series of twenty-five carefully superimposed sections plotted by drawing to produce a series of " cell charts." Each cell chart represents the nerve cell content of a 0.5 millimetre length of 'spinal cord. Examples taken from the third and fifth lumbar segments are shown in Figures 3 and 4.

The large motor nerve cells are arranged in columns whose disposition is remarkably constant at any given segmental level; the arrangement of the columns as seen in three dimensions is complex, and difficult to describe or illustrate. It would be inappropriate, in this article, to show the complete series of normal cell charts that were used as controls for the study of poliomyelitic cases; the detailed results that might be of value to other workers in this field will, it is hoped, be published later.

\section{THE REPRESENTATION OF THE MUSCLES OF THE LOWER LIMB IN THE MOTOR CELL COLUMNS}

Although previous work in experimental animals and in man suggested that the motor cell columns supply particular muscles or muscle groups, relatively little precise information was available about the representation of muscles in them in man. The sum of existing knowledge was well reviewed by Bok (1928). By comparing the presence or absence of cells in poliomyelitic spinal cords with the known activity in the muscles of the fourteen lower limbs concerned, much new information was obtained. The centres of innervation of all the

Vol. $37 \mathrm{~B}$, No. 4, NOVEMBER 1955

$B I_{(4)}$ 
main muscle groups in the lower limb have been identified; in Figure $\tilde{\pi}$ an attempt has been made to record the muscle representation in the cell columns at each segmental level.

In general, cell columns lying ventrally in the anterior horn supply the muscles in the proximal part of the lower limb, whereas those lying dorsally supply the more distal muscles

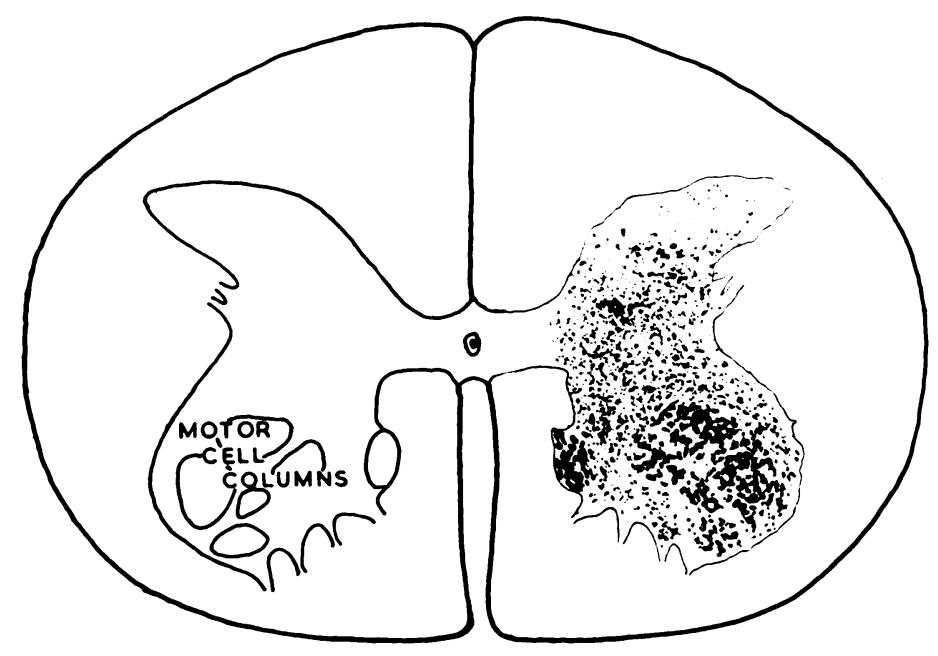

Fig. 3

Cell chart of the nerve cells in the grey matter of the third lumbar segment of a normal spinal cord.

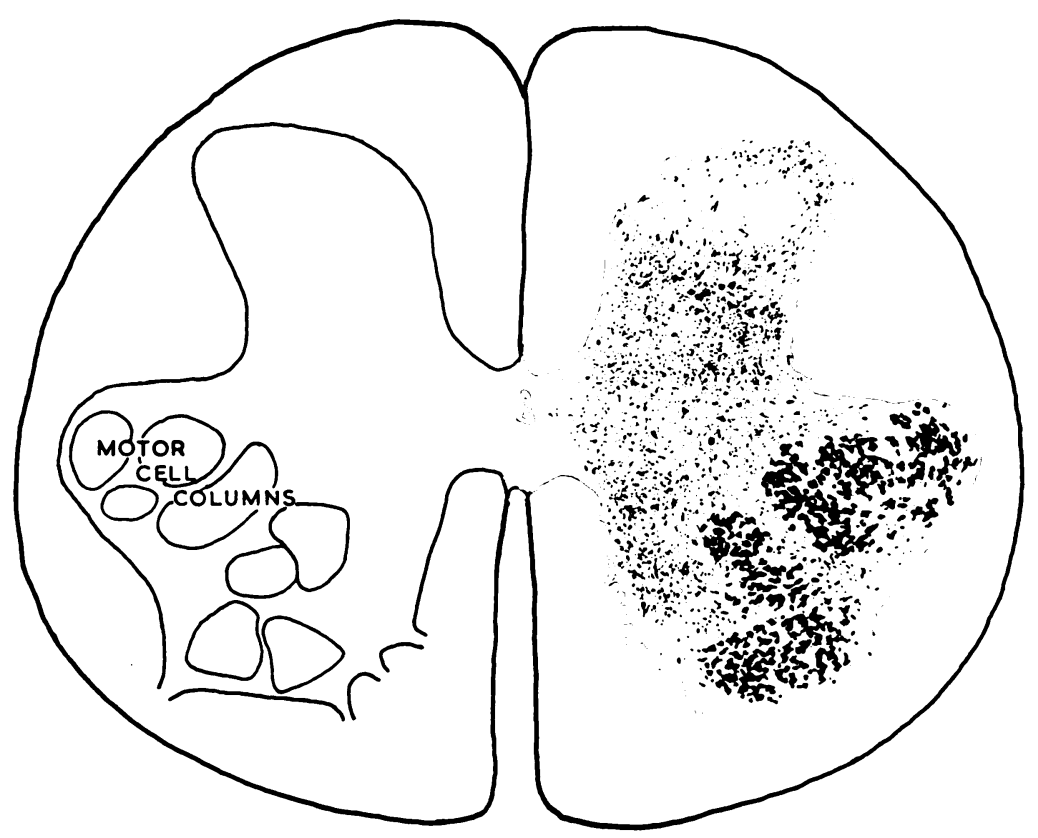

FIG. 4

Cell chart of the nerve cells in the grey matter of the fifth lumbar segment of a normal spinal cord.

of the leg and foot. Flexor muscles are supplied by columns situated medial and caudal to those supplying the corresponding extensor muscles. Some muscles, such as the hip flexors, the hip adductors and quadriceps are supplied by long cell columns; others, such as tibialis anterior, tibialis posterior, flexor digitorum longus and flexor hallucis longus are supplied by 


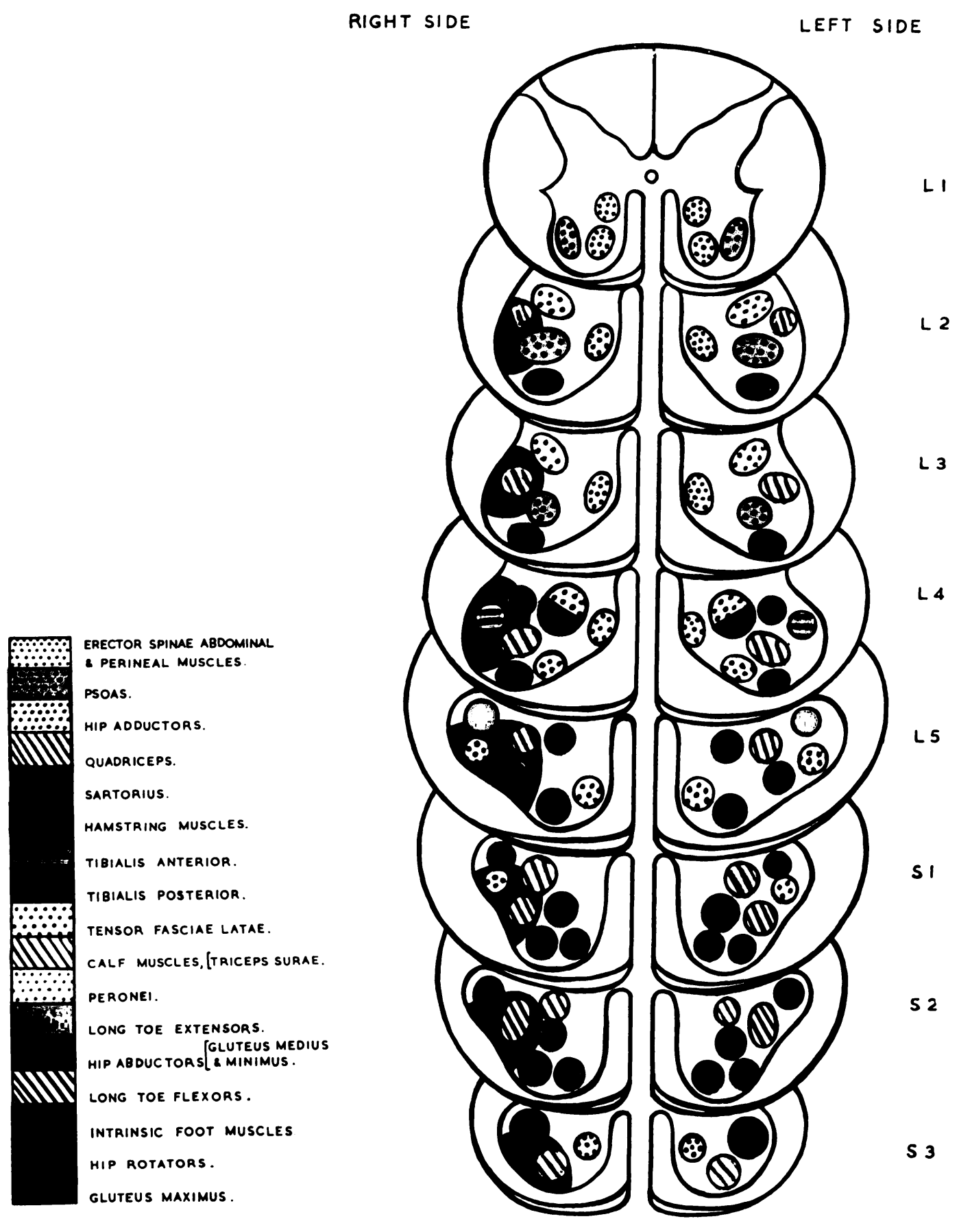

FIG. 5

The representation of the lower limb muscles in the motor cell columns of the lumbo-sacral spinal cord. The groupings of the columns are those that are the most characteristic in each spinal segment. Areas shown in black are those most liable to be affected by poliomyelitis. 
short columns. It is important to note that, for two reasons, the root innervation of a muscle or muscle group does not bear an absolute relation to the length of its cell column. Firstly, a muscle may receive its supply from two spinal segments (for example, tibialis anteriorL.4, 5), but its cell column does not necessarily extend through the whole length of either segment. Secondly, lumbar segments are almost twice as long as their numerical counterparts in the sacral segments. Thus the cell column that supplies a muscle innervated by the first and second sacral segments is much shorter than one that supplies a muscle innervated by the first and second lumbar segments.

\section{THE SITES OF MOTOR CELL DESTRUCTION IN POLIOMYELITIS}

The general distribution of motor cell destruction in the anterior horns of poliomyelitic spinal cords, as distinct from the loss of cells in individual cell columns mentioned above, showed several constant features.

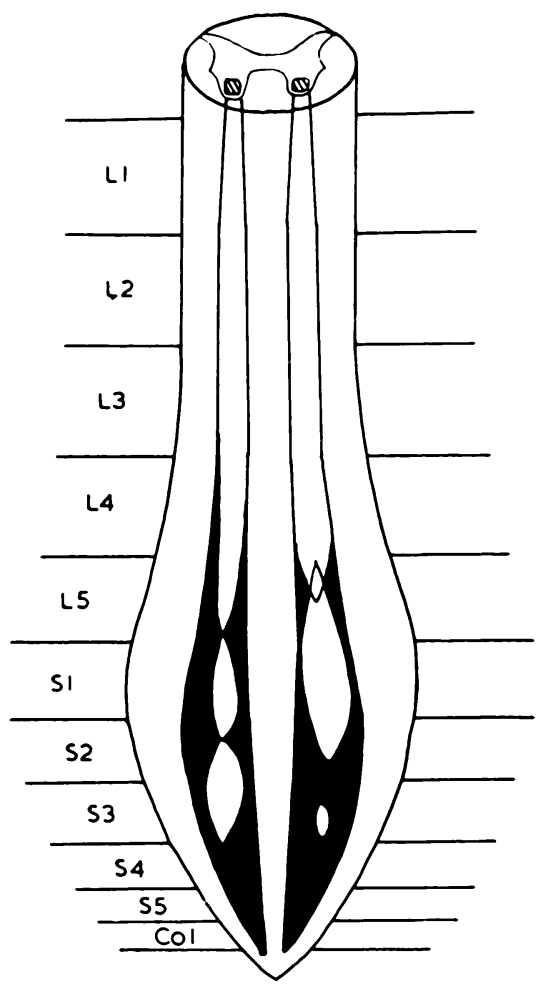

FIG. 6

A longitudinal analysis of the destruction of motor cells in the lumbo-sacral cord in a case of poliomyelitis with a moderate bilateral paralysis of the lower limbs.

Regions shown in black contain residual motor cells. Note the complete absence of cells in the upper lumbar spinal segments and the focal loss in the lower lumbar and sacral segments.
TABLE IV

The Relationship between Muscle Power and Residual Motor Cells in the Spinal Cord

\begin{tabular}{|c|c|}
\hline $\begin{array}{c}\text { Muscle power } \\
\text { (M.R.C. scale) }\end{array}$ & $\begin{array}{c}\text { Percentage of } \\
\text { residual motor cells }\end{array}$ \\
\hline 0 & $0-2$ \\
1 & $2-3$ \\
2 & $3-5$ \\
3 & $5-10$ \\
4 & $10-20$ \\
4 & $20-40$ \\
5 & over 40 \\
\hline
\end{tabular}

The second and third lumbar spinal segments were the most frequently and extensively attacked in all the cords. Segments caudal to this were less often affected, the third and fourth sacral segments being especially likely to be spared. A similar segmental incidence of motor cell destruction has been noted by others (Horányi-Hechst 1935, Peers 1943, Elliott 1945, 1947).

Destruction was found not to be diffuse but localised in discrete foci of varying length and width with interposed lengths of grey matter of more normal cell content. An example of this is shown in Figure 6, which represents the longitudinal distribution of the lesions in one of the spinal cords, reconstructed from more than three hundred cell charts.

In the transverse plane the centre of the anterior horn appeared to be the most vulnerable area at most segmental levels. The fifth lumbar segment, in which the anterior horn has its greatest transverse area, demonstrated this central loss very clearly; the example shown in Figure 7 was typical of that found in many cell charts in the poliomyelitic cords at this level. 
Motor cell destruction was always much more severe than would have been expected. One case in which there had never been any demonstrable weakness in any muscle in the lower limbs had suffered losses of up to $\mathbf{4 0}$ per cent of the normal number of cells in some cell columns. Far from there being any evidence that residual motor cells were functionally

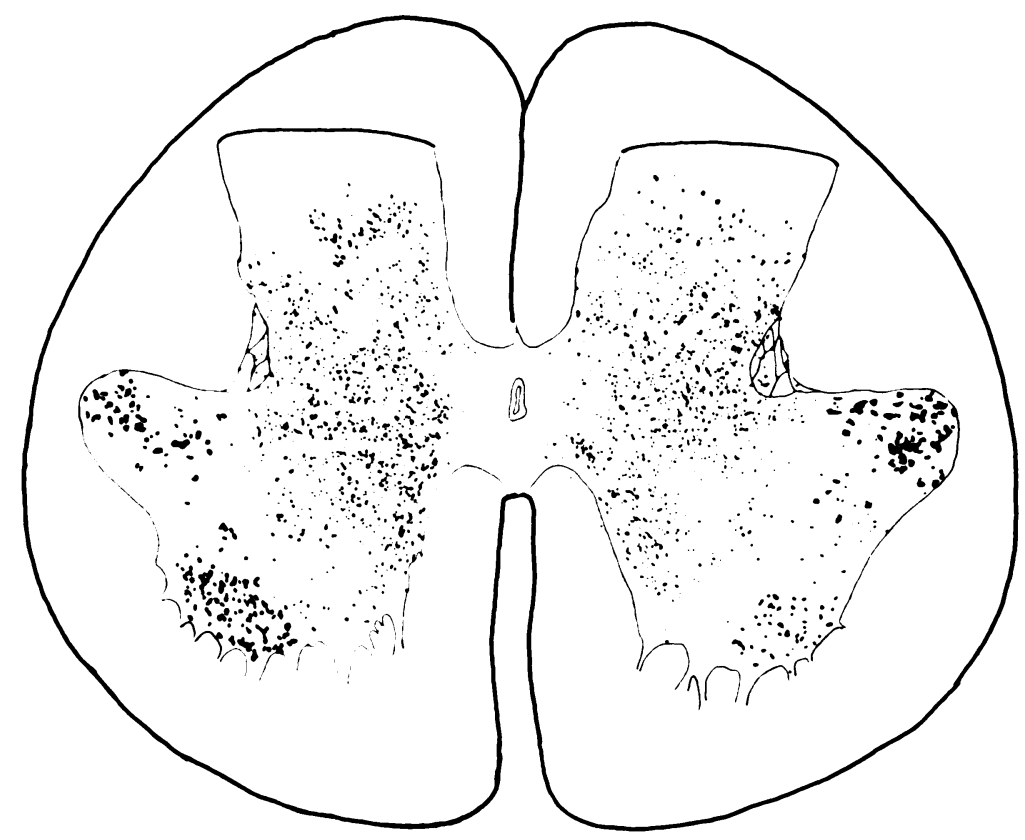

FIG. 7

Cell chart of the fifth lumbar segment of a poliomyelitic spinal cord. The centrally situated motor cell columns have been severely affected on both sides. (Compare with the normal in Fig. 4.)

inactive, it was surprising to discover how small a proportion of cells had been required to produce a useful contraction in the muscle they supplied. The residual power of a muscle was found to be closely related to the proportion of remaining motor cells that supplied it (Table IV).

\section{THE RELATIONSHIP BETWEEN THE DISTRIBUTION OF THE PARALYSIS AND THE DESTRUCTION OF MOTOR NERVE CELLS}

\section{AFFECTION OF MUSCLES}

The segmental incidence of muscle affection (Fig. 1) derived from the analysis of the clinical material agrees exactly with the general distribution of motor cell destruction described above. Since the upper lumbar spinal segments supply muscles in the region of the hip and thigh, while the lower lumbar and sacral segments generally supply the muscles of the leg and foot, it is easy to see why there is, apparently, a greater incidence of affection in proximal than in distal muscles in the limb. It is interesting to note that the hip muscle that derives its main supply from the sacral segments - that is, the gluteus maximus-is less frequently affected than other hip muscles (Table I). This is also true of the small external rotator muscles of the hip, though they are not shown in this Table.

The findings in the spinal cord also account for the large number of paralyses found in muscles such as tibialis anterior, tibialis posterior and the long flexor and extensor muscles of the toes. In Table $\mathrm{V}$, the ratios of paresis to paralysis in individual muscles are compared with the lengths of the motor cell columns that supply them. Muscles supplied by short 
columns of cells are the most frequently paralysed, those supplied by long columns are more likely to be paretic.

Figure 8 illustrates the probable mechanism responsible for this finding. A focus of motor cell destruction that severely affects the fourth and the upper part of the fifth lumbar spinal segment destroys almost all of the motor nerve cells that supply the tibialis anterior and most of those that supply the tibialis posterior. All other muscles are left with a proportion of residual motor cells sufficient to maintain normal power as judged by clinical examination.

TABLE V

The Relationship between length of Cell Column and the Ratio of Paresis to Paralysis in Muscles in the Lower Limb

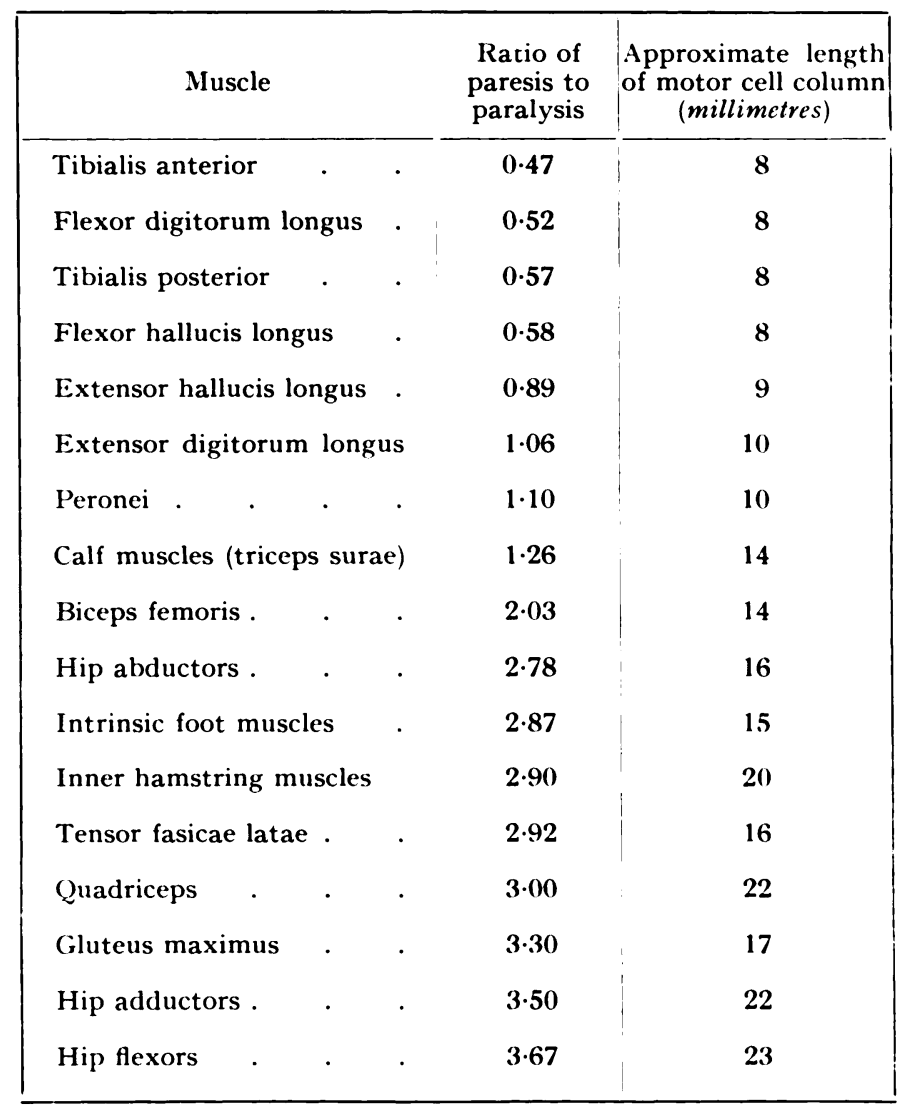

The shape of the curve in Figure 2 can now be explained. The high incidence of paralysis in muscles supplied by the lower lumbar and upper sacral segments is due to the fact that most of them-tibialis anterior, tibialis posterior, peronei and the long muscles of the toesare supplied by short columns.

All the features of the distribution of paresis and paralysis are satisfactorily explained in terms of lesions in the spinal cord. All the evidence is against a primary cause in the muscles themselves. If it were true that the distribution of paralysis was related to factors peculiar to certain muscles, movements or activities, evidence of it would be found in the disposition of cell destruction in the spinal cord. In fact, the focal loss of cells is completely independent of the boundaries of any one cell column; parts of cell columns are frequently obliterated in vertical or transverse planes. For the same reasons, the implication of higher centres as primary factors in the localisation of the paralysis is inadmissible. 
There is, as vet, no adecluate explanation for the greater incidence of motor cell destruction in the upper lumbar segments, and the progressively smaller incidence more caudally. In the transverse plane, the central sites of cell loss also found by Elliott (1945, 1947) in the anterior horn resemble those found by Krogh (1945) in experimental hyp-oxaemia of the spinal cord, and it is possible that vascular factors are partly responsible for them.
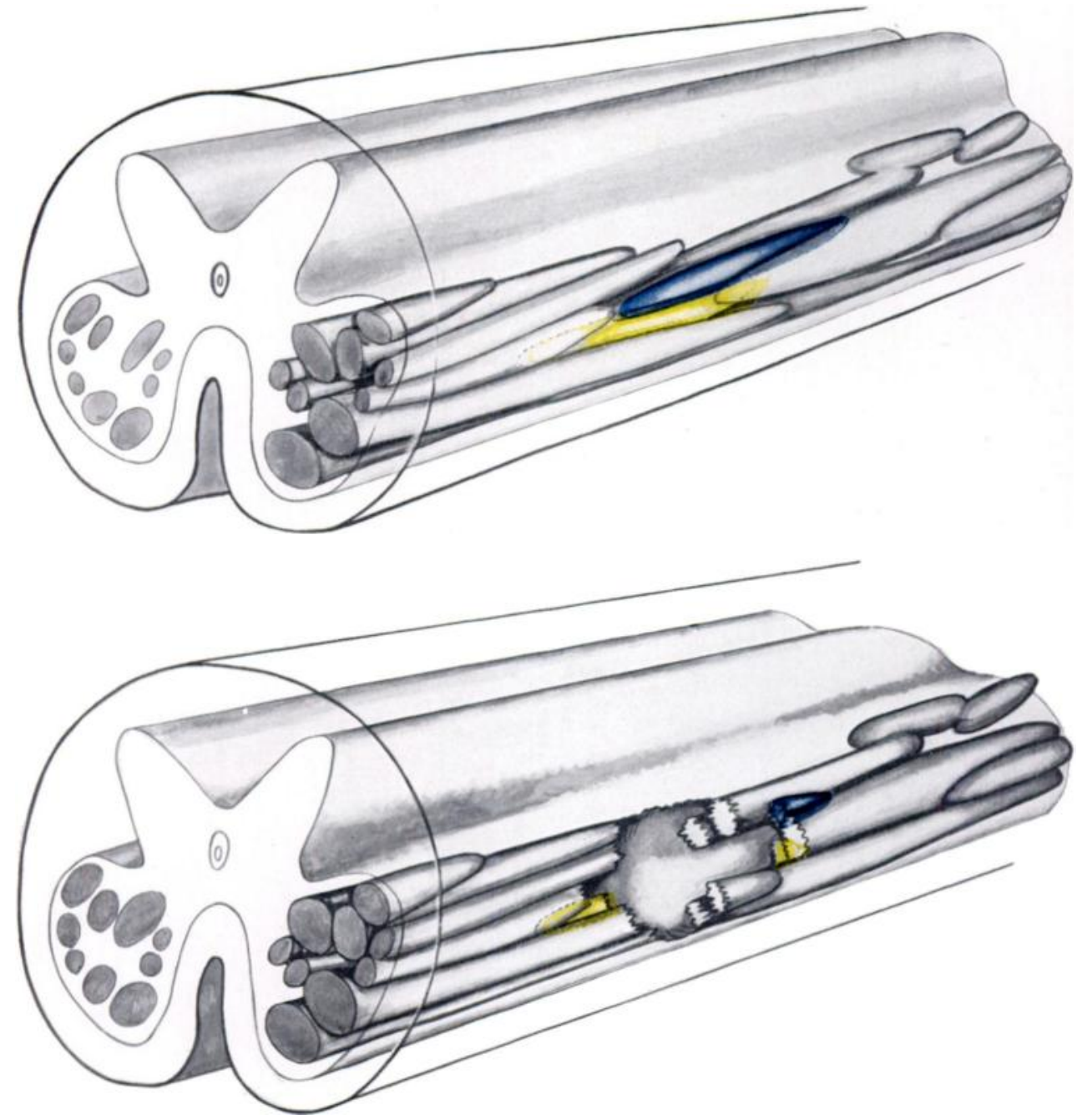

Fili. 8

I reconstruction of the cell columns of the third, fourth and fifth lumbar segments of the spinal cord. Hhoie the normal motor cell columns are shown: the two columns shown in colour are columns representing the tibialis anterior (bluc) and tibialis posterior (vellow). The visible cut end of the cord is the caudal end. Below all the motor cell columns in the lower part of the fourth and the upper part of the fifth lumbar segments have been obliterated by poliomyelitis. ()nly the short columns for the tibialis anterior (blue) and tibialis posterior (vellow) have been almost completely destroyed; only these two muscles will be paretic on clinical examination.

\section{ASSOCIATED PARALYSES}

When the whole of the motor column that supplied a muscle has been destroyed, it is likely that one or more adjacent motor columns that occupy the same length of spinal cord will be completely destroved or severely affected. This is reflected in the clinical distribution of muscle paralysis. For instance, the columns that supply extensor hallucis longus, extensor 
digitorum longus and peronei lie next to each other and occupy approximately the same length of spinal cord (Fig. 5). Paralysis of one of these muscles is, therefore, frequently associated with paralysis of the other two (Table III). Conversely absence of paralysis in one muscle is likely to be associated with absence of paralysis in the others.

Unusual associations, like that between the calf muscles (triceps surae) and the biceps femoris, can be accounted for in the same way, and would, indeed, be expected to occur, since their motor cell columns are so closely associated. The factor common to all strongly associated pairs of muscles is that their motor cell columns lie adjacent to one another and their segmental levels of supply correspond or overlap.

\section{ASSOGIATED PARALYSIS AND THE PROGNOSIS FOR PARALYSED MUSCLES}

In a previous paper (Sharrard 1955) the prognosis for a paralysed muscle was shown to be related to the degree of paralysis in muscles supplied by the same spinal segment. Associated paralysis between muscles may also be applied to determine prognosis. Ten muscles were chosen in which it may be important to know the prognosis for recovery. The probability of recovery to a functional power (M.R.C. grade 2, or greater) was worked out for each muscle 1) when both of its most strongly associated muscles were paralysed, 2) when one associated muscle was paretic or normal and the other paralysed, and 3) when both associated muscles were paretic or normal. The results are given in Table VI.

When both associated muscles were paralysed, the prognosis was very bad, particularly for the quadriceps, the hip abductors, tibialis anterior, tibialis posterior and the long toe extensors. When both associated muscles were paretic or normal there was an excellent prognosis for all muscles except tibialis anterior.

These results have lately been applied to the prognosis in individual patients and have been found to be valuable in making decisions about the management of the paralysis. A patient with paralysis of the quadriceps, hip adductors and hip flexors can be supplied, where it would be appropriate, with a caliper at an early date during the convalescent stage. The fear that the supply of an expensive instrument may be rendered invalid by recovery of the quadriceps will never be realised.

\section{PATTERNS OF PARALYSIS IN THE LOWER LIMB}

With the knowledge of the localisation of function in the motor cell columns that has been established above, it should be possible to deduce from the level of the paralysis in the muscles of any lower limb the approximate site and extent of lesions in the spinal cord, though not with such ease as in the diagnosis of a lesion in a peripheral nerve. Difficulties arise because, as Table IV indicates, a muscle is not paralysed unless the whole of its motor cell column has been affected. Even a residue of 10 per cent of intact motor cells may permit substantial activity in a muscle, and these intact cells may lie at the upper end, in the middle or at the lower end of the cell column.

There is another important difference between the analysis of peripheral nerve lesions and poliomyelitic lesions. Whereas lesions in peripheral nerves are much more often complete than partial in the transverse plane, lesions in the spinal cord frequently only involve part of the width of the grey matter at any given segmental level.

The distribution of muscle paralysis that might be expected to result from the existence of total or partial lesions of varying longitudinal extent in the grey matter of the lumbo-sacral spinal cord can nevertheless be worked out, and, conversely, all the common combinations or patterns of paralysis in poliomyelitic lower limbs can be explained in terms of one or more foci of motor cell destruction.

Figure 5 shows the position and size of cell columns for the lower limb muscles in the lumbo-sacral cord. The regions of the anterior horn that are shown in black in each segment are those most likely to be affected in partial lesions in the transverse plane. If all the cells 
in the second, third and fourth lumbar segments are destroyed, only the quadriceps, hip adductors, sartorius and tibialis anterior will be paralysed; the psoas and tensor fasciae latae will be paretic, but other muscles will be normal (Fig. 9, right side). Should the destruction involve the fifth lumbar segment as well, the tibialis posterior will also be paralysed, the hip

TABLE VI

The Percentage Probability of Recovery in Muscles in Relation to Affection of Their Associated Muscles

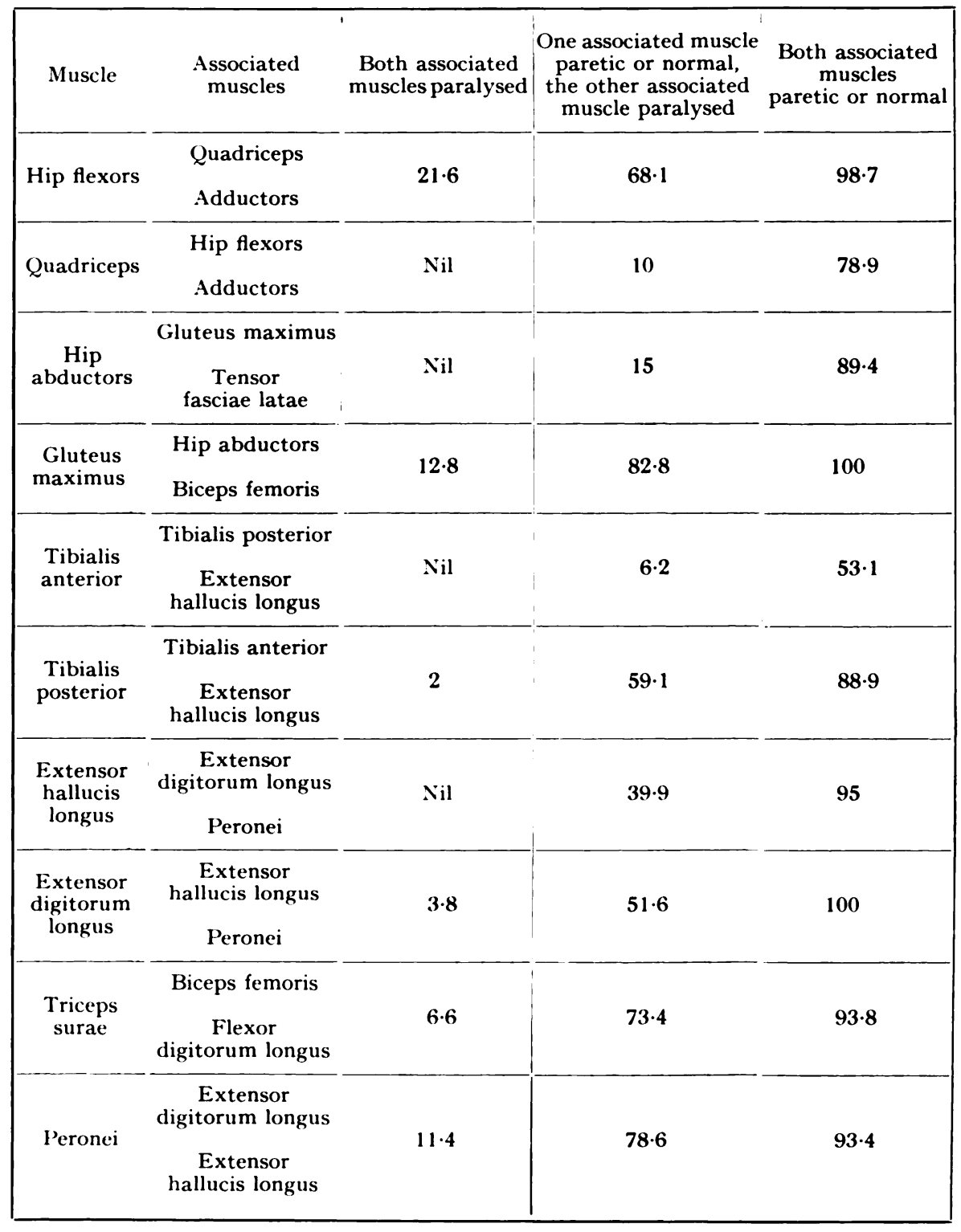

abductors and semimembranosus will be severely paretic and the long toe extensors and peronei mildly paretic (Fig. 9, left side).

The common isolated paresis of the tibialis anterior results from a partial lesion in the lower part of the fourth and the upper part of the fifth lumbar segments (Fig. 8). When the 


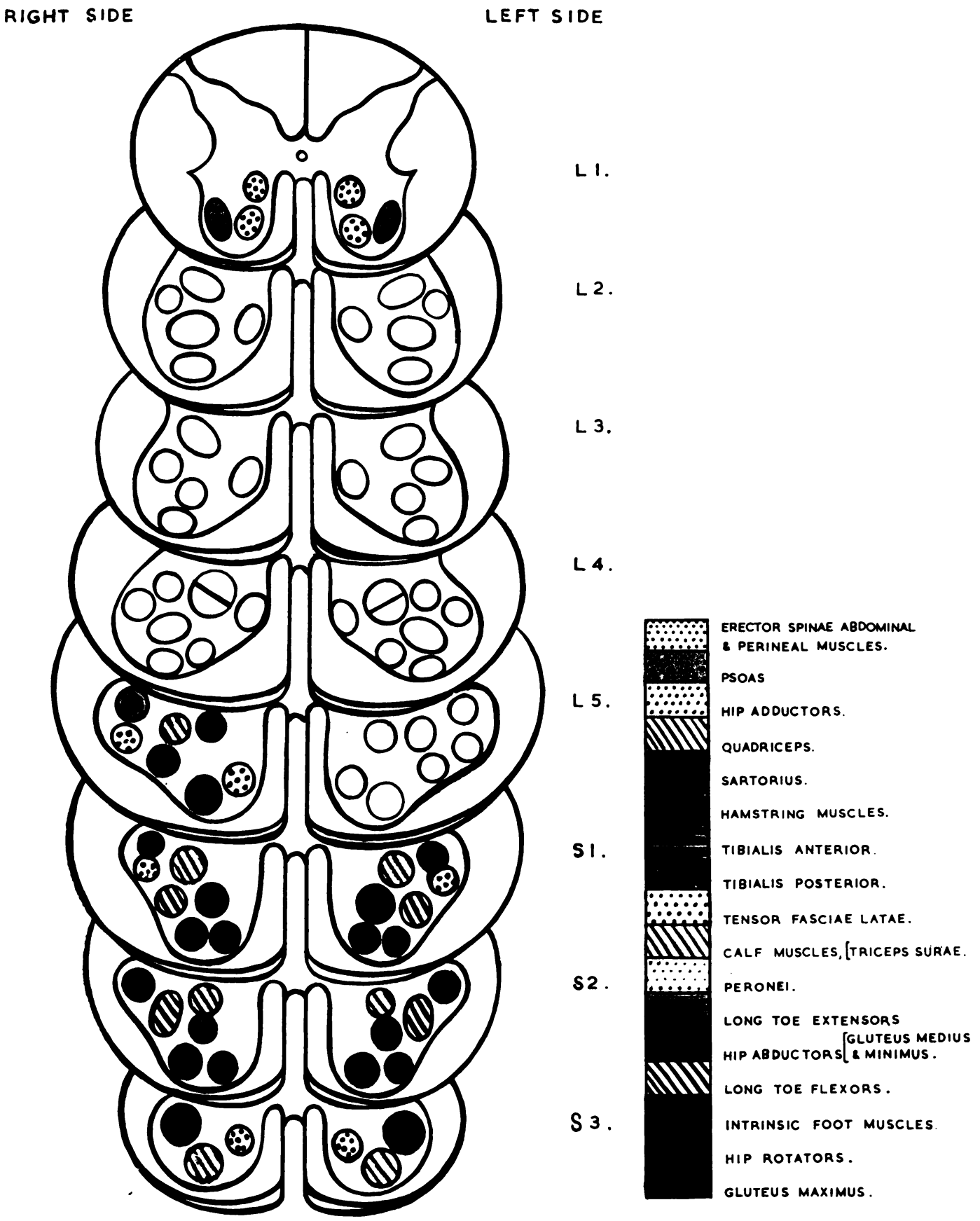

FIG. 9

A representation of motor cell loss in the lumbo-sacral spinal cord in poliomvelitis. ()n the right side, all the cells in the second, third and fourth lumbar segments have been destroved. Cell columns for the quadriceps, hip adductors, sartorius and tibialis anterior have disappeared; these muscles will be paralysed. The psoas and tensor fasciae latae retain a portion of their cell columns and will be paretic. On the left side, the second, third, fourth and fifth lumbar segments have been destroyed. The cell columns for the quadriceps, hip adductors, sartorius, tibialis anterior and tibialis posterior have disappeared; these muscles will be paralysed. The hip abductors, semimembranosus, long toe extensors and peronei retain a portion of their cell columns and will be paretic. 


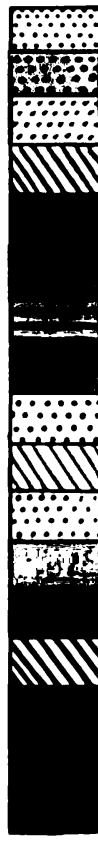

ERECTOR SPINAE ABDOMINAL - perineal muscles.

PSOAS.

HIP ADDUCTORS.

QUADRICEPS.

SARTORIUS

HAMSTRING MUSCLES.

TIBIALIS ANTERIOR.

TIBIALIS POSTEAIOR

tensor fasciae latae.

calf muscles, Ltaiceps surae

PERONEI.

LONG TOE EXTENSORS

HIP ABDUCTORS MINIMUS

LONG TOE FLEXORS.

INTRINSIC FOOT MUSCLES

HIP ROTATORS.

GLUTEUS MAXIMUS

RIGHT SIDE

LEFT SIDE

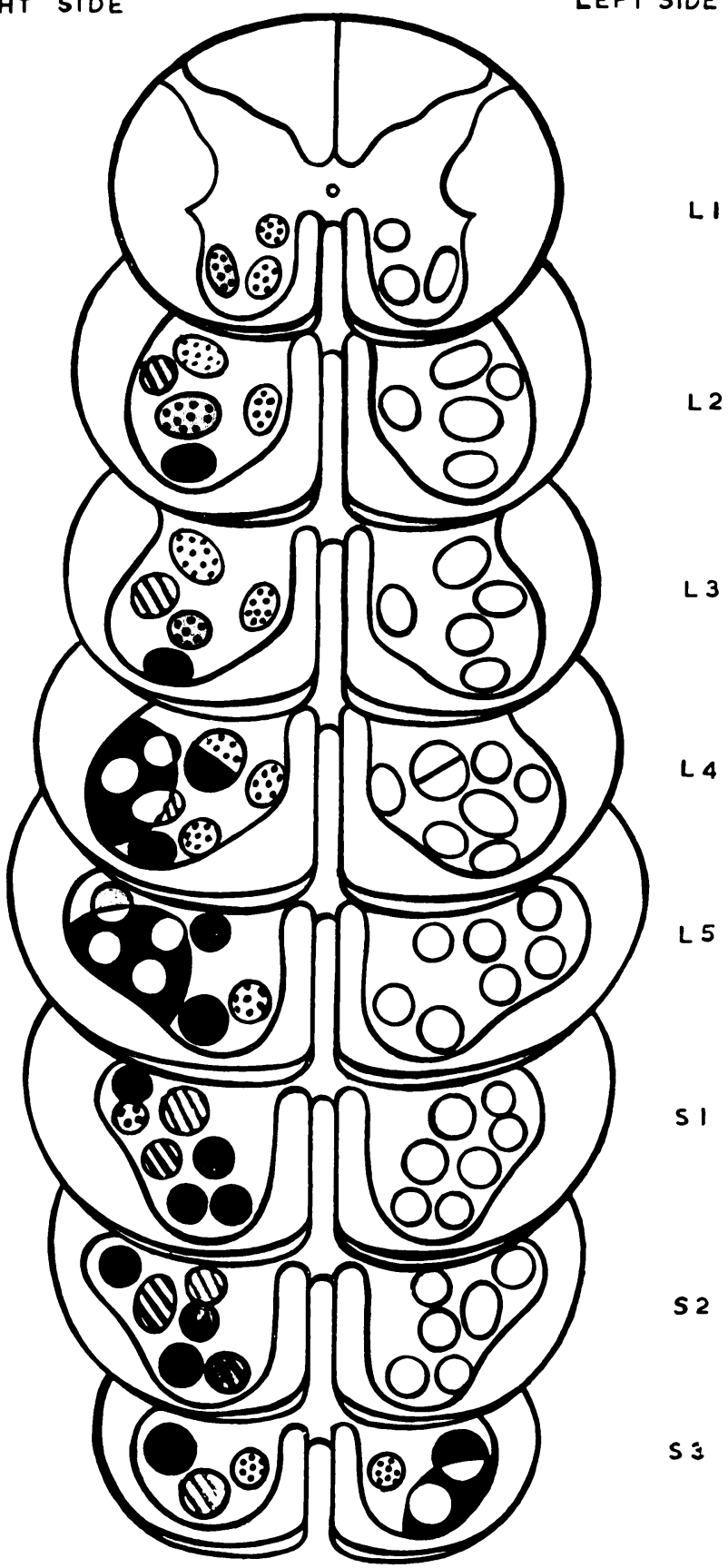

FIG. 10

A representation of motor cell loss in the lumbo-sacral spinal cord in poliomyelitis. On the right side, a partial lesion in the fourth and fifth lumbar segments has destroyed the cell columns for the tibialis anterior and tibialis posterior. All other muscles have retained a high proportion of their cells and the muscles concerned will not be clinically affected. On the left side, all the cell columns except those in part of the third sacral segment have been destroved. Only a portion of the column for the intrinsic muscles of the foot remains. The clinical result will be a flail lower limb in which only the intrinsic muscles of the foot are active. 
tibialis anterior and tibialis posterior are both paralysed, there is a partial lesion extending throughout both segments (Fig. 10, right side).

An extensive lesion that destroys all the motor cells in the lumbo-sacral segments gives rise to a flail lower limb in which only the intrinsic muscles of the foot and the peroneal muscles are active (Fig. 10, left side).

These few examples demonstrate how, by various combinations of destructive lesions in the grey matter of the spinal cord, the distinctive patterns of paralysis in poliomyelitis may be explained.

\section{THE PRACTICAL APPLICATION OF THESE FINDINGS}

Holdsworth and Hardy (1953) emphasised the importance of precise knowledge of the pathological lesion in the diagnosis, in the planning of treatment and in the assessment of the prognosis of traumatic paraplegia. In poliomyelitis the position is somewhat similar.

In the diagnosis of poliomyelitis at an interval after the acute stage, or when no febrile illness has been observed, the distribution of the paralysis alone may differentiate it from other lower motor neurone diseases. The paralysis in poliomyelitis is rarely precisely symmetrical. So frequently are the hip abductors, quadriceps or tibialis anterior affected that absence of paresis or paralysis in any of them in the presence of paralysis of other muscles in the lower limb makes a diagnosis of poliomyelitis unlikely. By contrast, in peroneal muscular atrophy the muscles most frequently affected in the early stages of the disease are the intrinsic muscles of the feet and peronei, a combination of paralysis rarely seen in poliomyelitis. Incidental to the comparison between the paralysis in these two diseases is the finding that the common bilateral symmetrical pes cavus, sometimes attributed to unrecognised paresis of the intrinsic muscles of the foot, is rarely the result of poliomyelitis. Even unilateral pes cavus, provided it is not a medial cavus (Pilcher 1955) or a calcaneo-cavus, is more often associated with spina bifida than with poliomyelitis.

The quantitative relationship between the loss of motor nerve cells and the residual power in muscles is particularly important in cases regarded as aparalytic in the acute stage of poliomyelitis. Although there may never have been any clinical paralysis, a considerable proportion of motor cells may have been damaged or destroyed. The nerve supply to some muscles, especially those supplied by short cell columns, may have been diminished by up to 60 per cent. Patients without paralysis are frequently allowed to walk within two or three weeks of the onset of the major illness. It is known that overstretching or over-fatigue can occur in muscles such as the hip abductors or tibialis anterior and may result in deterioration in power (Lovett 1915, 1917, Sharrard 1955). Paresis, previously undetectable, may be revealed later by the development of a limp or a valgus foot. It is probably wise, therefore, not to allow the resumption of full activity in an aparalytic case at too early a date, and to continue to look for evidence of paresis over a period of not less than six months.

In the management of the later stages-that is, after the first six weeks-the importance of accurate muscle testing has been stressed by Seddon (1955) and has been found to be of value in the prognosis of recovery in paretic muscles (Sharrard 1955). If the results of muscle testing are also used to reconstruct the probable site of major cell destruction in the spinal cord, the clinician will have a much clearer idea of what he is trying to treat, and what the chances are of recovery in paralysed muscles. The presence of associated paralyses (Table VI) may also help to define the prognosis for recovery of a paralysed muscle. Recovery can be expected in some muscles but the prolonged and uneconomic treatment of those that are beyond all hope can be avoided.

\section{SUMMARY}

1. The distribution of the permanent paresis and paralysis in the muscles of 203 lower limbs affected by poliomyelitis is analysed and related to the destruction of motor nerve cells in the grey matter of the lumbo-sacral cord. 
2. The tibialis anterior and tibialis posterior and the long muscles of the toes are more often paralysed than paretic; these muscles are innervated by short motor cell columns. Iuscles such as the hip flexors and hip adductors that are more often paretic than paralysed are innervated by long cell columns.

3. Muscles innervated by the upper lumbar spinal segments are more frequently affected than those innervated by the sarcal segments. This agrees with the segmental incidence of motor cell destruction found in poliomyelitic spinal cords.

4. Each muscle or muscle group is associated in paralysis with other specific muscles. For instance, the long toe extensors with the peronei and the calf muscles (triceps surae) with the biceps femoris. Associated muscles are innervated by adjacent motor cell columns. The probability of recovery in a paralysed muscle can be determined by reference to the degree of involvement in its associated muscles.

5. The distribution of the paralysis in an individual lower limb is determined by the site and size of foci of motor cell destruction. The cell loss in certain common patterns of paralysis is described.

6. The practical application of these findings is discussed.

I wish to acknowledge with thanks the help and guidance given to me by Mr H. J. Seddon, Director of Studies at the Institute of Orthopaedics, University of London, at which this work was undertaken under a grant from the Nedical Research Council. I am grateful to Dr H. A. Sissons and the members of the department of morbid anatomy who have collaborated and assisted in the pathological aspects of this study. The detailed results of the study of the first three poliomyelitic spinal cords were included in a thesis submitted to the University of Sheffield for the degree of Doctor of Medicine (1954).

\section{REFERENCES}

Bennett, R. L. (1952) Physical Medicine in Poliomyelitis-Points of Emphasis. Poliomyelitis. Papers and Discussions Presented at the Second International Poliomyelitis Conference, p. 261. Philadelphia, London, Montreal: J. B. Lippincott Company.

Вок, S. T. (1928) : I. Embryologie, gleichzeitig Einleitung zur Synaptologie. In Handbuch der Mikroskopischen Anatomie des Menschen. Herausgegeben von $W$. von Möllendorff. Band 4, Teil 1, p. 478. Berlin: J. Springer. BRCCE, A. (1901) A Topographical Atlas of the Spinal Cord. London: Williams and Norgate.

Covrtney, J. W. (1896): Acute Anterior Poliomyelitis. Boston Medical and Surgical Journal, 135, 617.

Flliot, H. C. (1942): Studies on the Motor Cells of the Spinal Cord. I. Distribution in the Normal Human Cord. American Journal of Anatomy, 70, 95.

Elliott, H. C. (1945): Studies on the Motor Cells of the Spinal Cord, iii. Position and Extent of Lesions in the Nuclear Pattern of Convalescent and Chronic Poliomyelitis Patients. American Journal of Pathology, 21, 87.

Elliott, H. C. (1947): Studies on the Motor Cells of the Spinal Cord, V. Poliomyelitic Lesions in the Spinal Motor Nuclei in Acute Cases. American Journal of Pathology, 23, 313.

Holdsworth, F. W., and Hardy, A. (1953): Early Treatment of Paraplegia from Fractures of the Thoraco-L umbar Spine. Journal of Bone and Joint Surgery, 35-B, 540.

Horányi-Hechst, B. (1935): Zur Histopathologie der menschlichen Poliomyelitis acuta anterior. I)eutsche Zeitschrift für Nervenheilkunde, 137, 1.

JAhss, S. A. (1917): Clinical Study of Four Hundred Cases of Anterior Poliomyelitis. Journal of the American Medical Association, 68, 754.

KROGH, E. (1945): Studies of the Blood Supply to Certain Regions in the Lumbar Part of the Spinal Cord. Acta Physiologica Scandinavica, 10, 271.

LEGG, A. T. (1929): An Analysis of the 1927 Epidemic of Infantile Paralysis in Mlassachusetts. Journal of the American Medical Association, 92, 31.

LEGG, A. T. (1937): An Analysis of the 1935 Epidemic of Infantile Paralysis in Massachusetts. New England Journal of Medicine, 217, 507.

Lovett, R. W. (1915): The Treatment of Infantile Paralysis. Journal of the American Medical Association, 64, 2,118 .

Lovett, R. W. (1917): Fatigue and Exercise in the Treatment of Infantile Paralysis. A Study of One Thousand Eight Hundred and Thirty-Six Cases. Journal of the American Medical Association, 69, 168.

VOL. 37 B, No. 4, NOVEMBer 1955 
Lovetr, R. W., and Lucas, W. P. (1908): Infantile Paralysis. A Study of 635 Cases from the Children's Hospital, Boston, with Especial Reference to Treatment. Journal of the American Medical Association, $51,1,677$.

Mirchell, J. I. (1925): The Residual Paralysis and Deformity of Anterior Poliomyelitis. Journal of Bone and Joint Surgery, 7, 619.

Peers, J. H. (1943): The Pathology of Convalescent Poliomyelitis in Man. American Journal of Pathology, $19,673$.

Pilcher, M. F. (1955): Tendon Transplantation in the Prevention of Foot Deformities after Poliomyelitis in Children. Journal of Bone and Joint Surgery, 37-B, 167.

Romanes, G. J. (1941): Cell Columns in the Spinal Cord of a Human Foetus of Fourteen Weeks. Journal of Anatomy, 75, 145 .

Seddon, H. J. (1955): Poliomyelitis. Part II-Treatment of Poliomyelitis. In British Surgical Practice. Surgical Progress, 1954, p. 162. Under the General Editorship of Sir E. Rock Carling and Sir J. Paterson Ross. London: Butterworth \& Co. (Publishers), Ltd.

Seddon, H. J., Agius, T., Bernstein, H. G. G., and Tunbridge, R. E. (1945) : The Poliomyelitis Epidemic in Malta 1942-43. Quarterly Journal of Medicine, N.S. 14, 1.

Sharrard, W. J. W. (1953): Correlation Between Changes in the Spinal Cord and Muscle Paralysis in Poliomyelitis-A Preliminary Report. Proceedings of the Royal Society of Medicine (Section of Orthopaedics), 46, 346.

Sharrard, W. J. W. (1955) : Muscle Recovery in Poliomyelitis. Journal of Bone and Joint Surgery, 37-B, 63. Skinнoj, E. (1949): Some Problems of Acute Anterior Poliomyelitis and its Sequelae. Copenhagen: Einar Munksgaard.

VAN Gehuchten, A., and Neeff, C. de (1900): Les noyaux moteurs de la moëlle lombo-sacrée chez l'homme. Névraxe, 1, 201.

Wickman, I. (1913): Acute Poliomyelitis (Heine-Medin's disease). Authorised English translation by J. Wm. J. A. M. Maloney, F.R.S. (Ed.). Nervous and Mental Diseases Monograph Series No. 16. New York: The Journal of Mental and Nervous Disease Publishing Company. 